Issues in Information Systems

Volume 18, Issue 3, pp. 100-106, 2017

\title{
THE USE AND IMPLEMENTATION OF A PROPRIETARY COMPUTER SYSTEM IN A POLISH HIGHER SCHOOL: A CASE STUDY
}

\author{
Matgorzata Cieciora, Polish-Japanese Academy of Information Technology, Malgorzata.Cieciora@pja.edu.pl
}

\begin{abstract}
The purpose of this paper was to present a case study that includes an original proprietary computer system developed for the Polish-Japanese Academy of Information Technology in Warsaw (known as GAKKO) and its role in improving quality under the Project "Kaizen - a Japanese quality in the Polish-Japanese Institute of Information Technology". The main goal was to analyze reasons, challenges and results of the decision to build a computer system from scratch in a technical school. Employees' opinions were gathered and analyzed. Results are presented. Discussion and implications are carried out. The main conclusion is that the successful implementation of the system was closely related to the possibility to engage in the work the School's own teachers and students - highly qualified IT specialists.
\end{abstract}

Keywords: Proprietary Computer System, Higher Education, GAKKO, Polish-Japanese Academy of Information Technology, "Kaizen" Project

\section{INTRODUCTION}

In modern companies and institutions the use of various computer systems aimed at optimizing work and reducing costs has become a standard. The market offers a wide array of such systems (see, e.g. Pieciukiewicz, 2011) - for example, CRM (Customer Relationship Management) systems, which help to manage contacts with clients, Business Intelligence systems, which allow for transforming data into information and information into useful knowledge or ERP (Enterprise Resource Planning) systems, integrating all business processes and the flow of key information. The choice of the right system is one of the most important decisions (usually taken at the strategic level) in the organization, especially that their functionality has a significant impact on the comfort and efficiency of employees and other stakeholders. Higher schools, which are currently subject to the processes of marketization are - alike commercial companies - paying more and more attention to the improvement of their performance. Therefore, they are increasingly making use of all kinds of IT systems. Some of them (e.g. the Warsaw University of Technology) attempt to implement ERP systems, a number of schools (including the University of Warsaw and the Jagiellonian University) use the USOS system (University System of Study Service), still others, like the Polish-Japanese Academy of Information Technology (PJAIT) are developing their own, original systems. This trend should be considered very positive, but one should also keep in mind that the implementation of such solutions is a major challenge for any organization, not just higher schools, as it requires a lot of work and funds, and the quality of the new tools and their compatibility with the needs of the organization is one of the key factors influencing the school's (or company's) effectiveness.

\section{RESEARCH METHODOLOGY}

The aim of this study is to present GAKKO - an original proprietary computer system, created for the Polish-Japanese Academy of Information Technology in Warsaw and its role in improving the quality of work of the School, in particular after the changes introduced under the Project "Kaizen - a Japanese quality in the Polish-Japanese Institute of Information Technology". The reasons for building GAKKO from scratch are presented, as well as some difficulties that had to be overcome during the process of building the system. There are also analyzed opinions and suggestions of both employees and students, made during the Project and after its completion, by means of the electronic suggestion box system named Suggester and acquired through in-depth interviews with the system's main users. Finally, some conclusions are presented. 


\section{RESULTS}

\section{Polish-Japanese Academy of Information Technology (PJAIT)}

Polish-Japanese Academy of Information Technology in Warsaw (PJAIT), formerly Polish-Japanese Institute of Information Technology (PJIIT) is a medium-sized higher school, with headquarters located in Warsaw. It was founded in 1994. The School has also a branch in Gdańsk and a research center in Bytom. The School offers studies in computer science (The Faculty of Computer Science), graphic design and interior design (The Faculty of New Media Arts), culture (The Faculty of Japanese Culture) and management (The Faculty of Information Management). It also has the right to grant the $\mathrm{PhD}$ title in the fields of computer science, mechanics and graphic arts, as well as the habilitation title in computer science.

\section{Reasons to build the School's proprietary computer system}

It should be stressed here that GAKKO was not the first computer system to be implemented in the School. The decision to build a proprietary system is not an easy one as there are a number of arguments for buying a commercial solution instead. Above all, the implementation process may be easier as the system has been used and tested in some other organizations (Kisielnicki, 2009, p. 204). The work can also be done faster (as the system is built up and ready to use) and the organization does not need to delegate its own workers to do the construction work, which is timeconsuming. Therefore, PJIIT decided to buy a system that had already been in use in a large public university in Warsaw. The decision turned out to be quite an unfortunate one. The main users of the system - workers of the students' office - reported a lot of problems with using the system. For example, the system did not have a userfriendly interface, required a large amount of time-consuming typing in data (instead of selecting from drop-down lists), did not have many useful functions such as student applications, creating reports or generating protocols. The division of functionalities was not compatible with organizational solutions of PJIIT and was typical of larger universities (e.g. the functionality of entering all the data of freshmen was assigned to the Enrollment Office while at PJIIT a significant part of such data was inserted by the students' office). A huge problem was the lack of technical support available on the spot. All requests for modifications to the system would be treated as paid additional services and took time to be fulfilled. The main objection against the system was that its modules could not be easily (if at all) integrated. Finally, two years after its purchase, the School's authorities made a decision to replace the system with a new, original one, which is now called: GAKKO.

\section{GAKKO system}

The GAKKO system is an integrated higher school computer system, developed in-house to meet the specific needs of Polish - Japanese Academy of Information Technology. Work on the system began in 2007 by a team led by longterm lecturers of PJIIT/PJAIT and experienced practitioners in the field of databases - Paweł Lenkiewicz, PhD, ViceDean of the Faculty of Computer Science in PJAIT, an author of many publications on databases, including a manual on administration of databases on the example of Microsoft SQL Server 2005 (Lenkiewicz, 2008) and Krzysztof Matejewski, MSc, a co-author, together with Lech Banachowski and Agnieszka Chądzyńska of a coursebook on relational databases (Banachowski, et al, 2009). The composition of the team has been changing, some of the work has been done by students of the Faculty of Computer Science as part of their graduation projects. The whole system operates using data stored and managed by a single, central database. Most of the functions are interrelated. These functions create processes and an omission of any of the components causes a loss of functionality of the entire process. The system has a modular structure. The modules - depending on their purpose - were designed as desktop applications and web-based applications (supported by web browsers). It should be mentioned that in the Academy there also function other systems, including modules of an ERP system (e.g. "Payroll"), modules of the Career Office portal and SharePoint DMS which were purchased under the "Kaizen" Project, or Suggester, created within the framework of the Project. They have been - or will be in the near future - at least partially integrated into the main system. One of the main advantages of GAKKO - apart from its high level of integration of the modules - is that all the necessary changes can be made in-house if there is such a need. The founders of GAKKO admitted, however, during in-depth interviews, that there is also the flip side of the coin - building, maintaining and developing the system is, indeed, quite costly and time-consuming, and students' work - although valuable - also needs teachers' time commitment. What is also worth mentioning is that, at least for the time being, it would be very difficult, if not 
impossible, to compare financial costs and benefits of implementation and maintenance of various IT systems in Polish higher schools as such analyses are not publicly available.

\section{“Kaizen" Project}

In 2012 the School began participating in a project titled "Kaizen - Japanese quality in the Polish-Japanese Institute of Information Technology" implemented under the Operational Programme Human Capital Priority IV , Measure 4.1, Measure 4.1.1., aimed at strengthening the potential of university teaching (Cieciora, 2015, p. 103). The Project involved a series of quality analyses. They were based on surveys carried out among students and staff (both at the beginning, as well as at the end of the Project) to examine their opinions concerning various aspects of the School's didactic process. The first online surveys were carried out between 15.12.2012 and 6.01.2013. They were addressed to students from all faculties (the student survey) and all employees, including persons employed on all types of contracts (the staff survey). They contained both closed-ended and open-ended questions - there was space to add one's own comments on all issues discussed. There were 356 respondents in the students' survey (both full-time and part-time students; most of them, around 30\%, were the students of the first year). 74 respondents filled in the staff survey. Most of them - around 63,5\% - were academic staff; 36,5\% were administrative workers.

\section{Functionality of computer systems - results of surveys conducted at the beginning of the Project}

As far as employees' opinions on the functionality of the systems that were in use at that time are concerned, about $45 \%$ of the respondents positively rated the GAKKO system, with less than $10 \%$ of negative responses. Some of them suggested the introduction of new functionalities. The respondents also shared comments about the desired changes concerning all of the then existing modules (students' office, recruitment, bursar's office, a virtual students' office, etc.). The most common suggestions concerned the need to integrate the existing systems, an introduction of the intranet and the creation of an electronic schedule. As for the opinions of students, they were quite similar to those of employees - about 52\% of the respondents positively (answer "definitely yes" and "rather yes") rated the functioning of the GAKKO system; about $44 \%$ chose the "no opinion" answer and less than $4 \%$ expressed a negative opinion (answers "probably not" and "definitely not") (Cieciora, 2015, pp. 106-120).

\section{Actions taken within the "Kaizen" Project}

After the analysis of the information from surveys and interviews with employees involved in selected processes, a number of project actions, including those related to computer systems were carried out. The GAKKO system was expanded; there were added new functions, such as, e.g. the "Chair" module, allowing teachers and decision makers to acquire remote access to data concerning classes (including lists of student groups, grades, results of surveys, final defenses data), or the "Schedule" module that allows students and employee to have remote access to the most current version of their own, personalized timetables. Attempts were made to minimize the "paper" document workflow by integrating existing information systems with a newly implemented ERP system (which includes such modules as "Payroll" or "Invoices and inventory management") and the implementation of the SharePoint DMS tool. It is also worth mentioning that the Career Office portal was significantly expanded and an electronic suggestion box named Suggester was created from scratch (Cieciora, 2015, p.121-122).

\section{The functionality of computer systems - the results of surveys conducted at the end of the Project}

At the end of the Project, between 16.10 and 24.10.2014, the staff and student surveys were carried out again. The respondents were asked the same questions as in the first questionnaire; there were also added questions concerning solutions worked out and implemented during the Project. 56 (both full-and part-time) students and 55 employees (around 69\% - academic staff, 17\% - administrative workers) participated in the final Project surveys. The staff survey was filled in by 55 respondents, 31 men, and 24 women. The vast majority of respondents identified themselves as a researcher and teacher (around 69\%). The student questionnaire was filled in by 56 students -32 men and 24 women. The proportions of full- and part-time students were almost equal. The results of survey from 2012 and 2014 were compared. The dynamics of the changes was calculated by comparing the scores from 2014 and 2012. In the staff survey "Functionality of the GAKKO system" obtained the highest percentage change - the difference between the 
average of 2012 (3.0706) and the average of 2014 (4.0545) was 0.9840. Respondents either positively assessed new modules introduced in the framework of the "Kaizen" Project, such as the SharePoint DMS (introduced with the aim of improving the flow of documents $-67 \%$ rated it as "good" or "very good), a new electronic timetable ( $84 \%$ of positive responses) or modules: Wiki, blog, the ability of assessing and commenting on content (62\% of positive opinions), or had no opinion on the subject - e.g. as far as Suggester is concerned, 38\% of respondents rated it positively, and $29 \%$ "had no opinion" on this tool. Opinions of students were quite similar to those of employees (it should be noted, however, that students more often "had no opinion" about a new functionality) - for example, $83 \%$ of respondents expressed satisfaction with the new electronic timetable, but as many as $80 \%$ of respondents "had no opinion" on the new modules: Wiki and blog, and 71\% of respondents "had no opinion" on Suggester (Cieciora, 2015, pp. 126 - 136).

\section{GAKKO - the present situation (after the completion of the "Kaizen" Project)}

The GAKKO system has the following basic functions:

\section{Enrollment process service:}

- registration of a candidate in the enrollment portal;

- exchange of documents between the candidate and the Enrollment Office;

- registration of the candidate as a student of PJAIT and passing the information to the appropriate students' office.

\section{Registration and control of student data:}

Complete data entered during the student enrollment process is forwarded to the appropriate students' office, which takes control of it, with the right to edit the data for the following purposes:

- $\quad$ establishing the student's status (student, expelled, removed from register, leave of absence, graduate);

- registration of students for selected study programs in subsequent semesters and assignment of students to appropriate student groups;

- issuing the necessary certificates to students.

- creation of letters submitted to students (e.g. the decision of enrollment, the decision of expelling, etc.);

- printing of diplomas and supplements;

- insight into the learning outcomes of students with full information about any shortcomings in relation to the curriculum.

\section{Planning lectures and classes:}

- entering the curriculum;

- creating student groups and assigning students to them;

- planning a class schedule (based on the curriculum) for student groups;

- entering the names of teachers assigned to teach the classes in the class schedule;

- publication of general and personalized schedules;

- additional function - booking rooms in PJAIT buildings for activities outside the regular schedule and for non-teaching purposes.

\section{Management of the teaching staff of the Academy:}

- assigning employees to chairs;

- assigning to chairs subjects which they are responsible for;

- assigning to teachers subjects which they are responsible for.

\section{Providing additional information:}

- providing student survey results to teachers, their supervisors, deans, heads of chairs (within their prerogatives);

- providing teachers with information on subjects which they are responsible for;

- entering information about the teachers' duty hours. 


\author{
Supporting processes of theses supervision and final defenses: \\ - creating groups of students involved in the final thesis project; \\ - entering a title for the thesis; \\ - granting the status of the process of work (active, dormant, completed); \\ - assigning teaching roles to the process of final defense (e.g. supervisor, reviewer); \\ - $\quad$ entering reviews of theses; \\ - registration of the thesis defense process - date of the defense, composition of the commission, final \\ assessment.
}

\title{
Registration of teachers' hours of work:
}

Basing on the schedule and assignment of teachers to classes there are created reports that allow to monitor hours of work of teachers and form the basis for financial settlements.

\section{Supporting the process of blended learning and remote learning:}

- creating courses (may match the classes of particular subjects) and assigning students to courses (could be the equivalents of student groups);

- publishing information addressed to students of the courses;

- publishing a calendar of events of the course;

- publishing didactic materials (in any file format) for the courses; the materials may be stored in repositories (archives);

- publishing lectures in HTML files;

- collecting students' work by opening appropriate folders to which assignments can be uploaded;

- organizing educational process through systems of lessons, tasks, quizzes and tests,

- implementation of the "chats" in the text, audio, or video mode, with an option of sharing the teacher's desktop and capturing the students' desktops;

- other functionalities: Wiki, blogs, FAQs, forum.

\section{Registration of learning results:}

- creating and filling in transcripts;

- the option to fill in an electronic form is limited in time; deadlines are set by deans, and after the deadline, the only option for a teacher who needs to make any changes in the transcript is to do it through the students' office module (i.e., by coming in person to the students' office);

- enabling teachers to have an insight into the records archive;

- enabling students to have an insight into their learning results;

- enabling the printing of student examination cards.

In PJAIT the use of traditional paper student's books (indexes) has been eliminated. All records of the teaching process are stored digitally. Paper documentation is stored in the form of printouts of digital records.

\section{Generation and control of students' payments due:}

In the GAKKO system, students' payments due (registration fee, tuition, the fee for a repeated course etc.) are automatically generated. The amount of the payment due is entered in a GAKKO module. The settlements of payments are made in an accounting system which is not part of GAKKO. The basis for settlements of payments is the information about the payments due transferred from GAKKO and data from bank transfers (currently recorded outside GAKKO). Controlling the settlements is possible thanks to the data transferred from the accounting system to GAKKO. The billing status of the student is visible to employees of the students' office and can provide the basis for changing the student's status. Each student has an insight into the current status of their settlement with the Academy.

\section{Student applications:}

GAKKO supports the process of submitting and processing applications of students. The application is submitted in electronic form and sent to the appropriate decision maker. The answer to the application is sent to the student also in the electronic way. 


\section{Tracking the current state of enrollment:}

The data recorded in the GAKKO database allows for tracking the current state of enrollment, together with the option to compare the results with the data from previous academic years. This provides the basis for predicting the final results of the enrollment, which allows for making adjustments to the schedule somewhat in advance, even before the end of the enrollment.

\section{Data reports:}

The data stored in the GAKKO database is used to create reports for GUS (The Central Statistical Office of Poland) and the POL-on system (an integrated information system for higher education, which supports the work of the Ministry of Science and Higher Education).

\section{E-portfolio:}

A specialized system of storing and sharing teaching materials and student work (created during the educational process).

\section{Surveys:}

A specialized system to generate, distribute and analyze survey results. It allows one to create virtually any kind of survey, to define groups of respondents, to collect and analyze the survey results.

Calculation of teachers' hours of work and remuneration: Student groups are formed on the basis of the entries of students into a given semester. The schedule is created based on the curriculum for the given semester (it includes the student group, subject, room, hours of the classes, types of classes). For particular classes, there must be assigned teachers conducting these classes. There is an option in the system to split a course into hours taught by different teachers and calculate their payments accordingly. Settlements of teachers' payments are made on the basis of this data, taking into account the number of hours taught as well as the type of classes (lectures, laboratories, etc.) (Matejewski, 2017)

\section{Entries from the Suggester system:}

After the completion of the "Kaizen" Project opinions and suggestions on various aspects of the didactic process can be reported via the electronic system called Suggester, available to every employee and student of the Academy after logging in. Since the end of the Project till the end of February 2017 several suggestions for GAKKO were submitted this way. They concerned, for example, the following issues:

- a suggestion of creating a system that will send a mail message about the addition of a lecture/tasks/materials etc. in the student's account in the EDUX e-learning module, as well as the information about upcoming deadlines for submission of tasks;

- a report on incorrect display of mathematical symbols in lectures accessible from the electronic platform, e.g. in cases when using electronic browsers other than Internet Explorer;

- a report on an inoperative link;

- a suggestion of the need to develop a functionality of informing about the appearance of new entries on the platform;

- a suggestion of a common logon to all modules of the system (Cieciora, 2017).

\section{DISCUSSION AND CONCLUSIONS}

In PJAIT a decision was made to build the School's own, original, integrated computer system called GAKKO. The main reason for the decision was the high level of dissatisfaction with the previous, commercial application. The first version of GAKKO was created in 2007 and it has been upgraded and modified ever since. Most of the modules used in the Academy are parts of GAKKO. The results of surveys conducted within the framework of the "Kaizen" Project allow for drawing a conclusion that the system is rated positively by the academic community and has significantly improved the efficiency of many processes of the School, among them as important ones as financial settlements (of both students and teachers), student documentation, planning lectures and classes, applications of students, sharing teaching materials and management of data to be passed on to external stakeholders such as POL-on and GUS. The 
successful creation of a highly integrated system, tailored to the needs of the School was possible thanks to the specific nature of the School (PJAIT is a school whose largest and most important faculty is the Faculty of Computer Science), which employs highly qualified specialists in databases and can also use the skills and knowledge of IT students. The result is a system that highly meets the needs of the Academy, though it should be stressed that it needs constant upgrading. The main cost of the solution is the time that the above mentioned specialists have had to devote to build, maintain and develop the system.

\section{SUMMARY}

Nowadays, in the times often referred to as the Age of Information, various computer systems have become some of the most important tools in the hands of managers. Well-chosen can significantly improve the comfort of employees, facilitate communication within the organization and with external stakeholders, improve quality and efficiency, reduce costs and, as a result, increase the level of customer satisfaction. The decision on the choice of the system is thus one of the most important strategic decisions of the organization. This also applies to higher schools, which, functioning in the market economy, are increasingly turning to solutions used so far in the business world. Polish higher schools are beginning, therefore, to implement such systems. One way of acquiring a system that would be efficient and well-adapted to the needs of the school is to build it from scratch. This is not an easy task; the case of PJAIT and its GAKKO can be considered a success, the source of which has been, primarily, top-class specialists their own teachers and students who have worked on the system. It should also be remembered that the system must be constantly modified so that its functionality will well match the ever-changing needs of the organization. The aim of this study was to present a single, proprietary computer system and discuss benefits and challenges related to the choice of such a solution for a higher school. Conclusions from the study could be helpful in analyses concerning the implementation of IT tools in higher schools. The article focused on a case study of one school; an interesting and important topic for further research would be an assessment of the effectiveness of various solutions (e.g. introduction of USOS or commercial ERP systems) implemented by a large number of higher schools.

\section{REFERENCES}

Banachowski, L. Chądzyńska, A., Matejewski, K. (2009). Relacyjne bazy danych. Wykłady i ćwiczenia. [Relational databases. Lectures and classes]. Warszawa, Wydawnictwo PJWSTK.

Cieciora, M. (2017). Raport ze zgłoszeń systemu Suggester. [Report on entries from the Suggester system]. PJATK, Warszawa (internal document).

Cieciora, M. (2015). Zarządzanie jakościa procesu dydaktycznego w szkole wyższej. Kaizen-japońska jakość w Polsko-Japońskiej Akademii Technik Komputerowych. [Quality management of the didactic process in a higher school. Kaizen - Japanese quality in Polish-Japanese Academy of Information Technology]. Warszawa Wydawnictwo PJATK.

Kisielnicki, J. (2009). MIS Systemy informatyczne zarządzania. [MIS IT management systems]. Warszawa, Wydawnictwo PLACET.

Lenkiewicz, P. (2008). Administrowanie bazami danych na przyktadzie Microsoft SQL Server 2005. [Administration of databases on the example of Microsoft SQL Server 2005]. Warszawa, Wydawnictwo PJWSTK.

Matejewski, K. (2017). Opis funkcjonalności GAKKO. [A description of functionalities of GAKKO]. PJATK, Warszawa (internal document).

Pieciukiewicz, T. (2011). Komputerowe narzędzia wspomagania zarządzania. [Management support computer systems]. Warszawa, Wydawnictwo PJWSTK. 